\title{
DuPont analysis was used to evaluate the operation of non-profit medical institutions in Chongqing
}

\author{
Guo Tian ${ }^{1}$, Liu weiwei ${ }^{2 *}$ \\ ${ }^{1}$ Chongqing Institute of Health Education, Yubei District, Chongqing \\ ${ }^{2}$ Medical and Social Development Research Center, School of Public Health and Management, Chongqing Medical University; National \\ Health and Social Risk Early Warning Collaborative Innovation Center Chongqing 400016
}

\begin{abstract}
It has been nearly eleven years since the reform of China's medical and health system entered the final sprint stage in early 2008. During this period, great changes have taken place in China's medical system, which has had a huge impact on the operation of public hospitals in China. This paper analyzes the key financial indicators of public hospitals in Chongqing from 2007 to 2017, including revenue and expenditure situation and structure, assets and liabilities situation and structure, finds out the problems in operation and puts forward suggestions. The key financial indicators of public hospitals in Chongqing were analyzed and evaluated by trend analysis, ratio analysis and DuPont analysis. The total revenue and expenditure of public hospitals in Chongqing increases with GDP year by year, the structure of revenue and expenditure has changed greatly, the debt level is reasonable, and the operating capacity is at a low level. The balance of drug revenue and expenditure in public hospitals is unbalanced, so it is necessary to strengthen the implementation of drug price adjustment plan; Public hospitals should strengthen the cost control, especially the cost control of drug expenditure, in order to meet the requirements of national policies and improve their own operating capacity.
\end{abstract}

\section{Introduction}

The basic data of this study comes from the statistical yearbook of Chongqing Health and family planning commission from 2007 to 2017. Firstly, this paper uses trend analysis method, ratio analysis method and other methods to make descriptive statistics on the income, expenditure, assets, liabilities and other financial indicators of non-profit medical institutions in Chongqing, and then uses DuPont financial analysis method to analyze the financial indicators. The purpose of this paper is to put forward suggestions to improve the operation and profitability of non-profit medical institutions in Chongqing under the background of medical reform and upgrading.

This paper divides the non-profit medical institutions in Chongqing into four categories: hospitals, basic medical and health institutions, professional public health institutions and other health institutions. Among them, hospitals include two sub categories: municipal and district level hospitals, and grass-roots medical and health institutions include community health service center, community health service station, street health hospital, township health hospital, village health room, outpatient department, clinic and medical room. The classification is as follows Table 1:
Table 1: Non-profit medical institutions

\begin{tabular}{|c|c|}
\hline \multirow{2}{*}{ hospital } & Municipal Hospital \\
\hline & District and county hospitals \\
\hline \multirow{7}{*}{$\begin{array}{l}\text { Primary medical } \\
\text { and health } \\
\text { institutions }\end{array}$} & Community Health Centre \\
\hline & Community Health Station \\
\hline & Street Health Center \\
\hline & Township Health Center \\
\hline & Village clinic \\
\hline & The outpatient department \\
\hline & Clinics and infirmaries \\
\hline $\begin{array}{l}\text { Professional } \\
\text { public health } \\
\text { institutions }\end{array}$ & / \\
\hline $\begin{array}{l}\text { Other health } \\
\text { institutions }\end{array}$ & / \\
\hline
\end{tabular}

\section{Material and Methods}

According to DuPont financial analysis system, return on equity can be decomposed into multiple indicators to analyze the hospital's operating results and financial situation from different perspectives [3].Using DuPont analysis method, return on net assets = business balance ratio $\times$ Turnover of total assets $\times$ Equity Multiplier: the

* Corresponding author: 1ww102551@cqmu.edu.cn 
average business balance rate, average total asset turnover rate and average equity multiplier of non-profit medical institutions in Chongqing from 2007 to 2017 are substituted into the above formula to calculate the return on net assets of each year

\section{Results \& Discussion}

\subsection{Descriptive statistics of main financial indicators of non profit medical institutions in Chongqing}

\subsubsection{Changes of total revenue and expenditure of non profit medical institutions in Chongqing}

On the whole, the total income and total expenditure of non-profit medical institutions in Chongqing from 2007 to 2017 kept a synchronous increase and decrease with the GDP of Chongqing. Because the absolute value of total income, total expenditure and GDP is large, and the value of GDP is much higher than that of total income and total expenditure, in order to compress the variable scale and more intuitively observe the changes of total income and expenditure and GDP, the results of natural logarithm of total income, total expenditure and Chongqing GDP are taken as abscissa in Figure 1. According to the data from 2007 to 2017, the proportion of the total income of nonprofit medical institutions in Chongqing's GDP fluctuates around the average value of $3.79 \%$. In 2008 , the annual growth rates of total income and total expenditure were nearly $100 \%$; In 2009 , both total income and total expenditure decreased by about $20 \%$ from 2008, equivalent to an increase of about 57\% from 2007.

\subsubsection{Analysis on income composition of non-profit medical institutions in Chongqing}

From 2007 to 2011, there was no income from sanitary materials in all non-profit medical institutions in Chongqing. Since 2012, the income from sanitary materials began to appear, and the proportion of the income from sanitary materials in the total income increased year by year from $3.63 \%$, reaching $5.52 \%$ in 2017 , with an average annual growth rate of $7.26 \%$. Since 2009 , the proportion of drug revenue in total revenue has continued to slow down, with an average annual growth rate of $-3.18 \%$. From 2007 to 2017, the proportion of outpatient income and inpatient income in the total income has been maintained at about $23 \%$ and $35 \%$, with little change. The proportion of total medical income (the sum of outpatient income and inpatient income) in the total income has been stable at about $58 \%$. The proportion of financial subsidy income and superior subsidy income in the total income is stable at about $9 \%$ and $0.5 \%$. The income composition of non-profit medical structure in Chongqing.

\subsubsection{Analysis of expenditure composition of non- profit medical institutions in Chongqing}

2012 is the watershed of significant changes in the expenditure structure. Before 2012, the proportion of medical expenditure in the total expenditure was about $90 \%$. Since 2012 , the proportion has dropped sharply and stabilized at $60 \%$. Part of the reduced cost of medical expenditure has been transferred to drug expenditure and public health expenditure. The proportion of drug expenditure in total expenditure increased by leaps and bounds from the average level of less than $2 \%$ to the average level of nearly $27 \%$ in 2012 , and the proportion stabilized at about $25 \%$ in 2012-2017. On the whole, from 2007 to 2017, the structure of medical expenditure, public health expenditure and drug expenditure of all non-profit medical institutions in Chongqing has changed greatly since 2012 , but the sum of the three has accounted for about $90 \%$ of the total expenditure, while the sum of administrative expenses and financial subsidies has accounted for about $10 \%$ of the total expenditure.

In addition, it is worth noting that there is no management cost in the expenditure of all non-profit medical institutions in Chongqing from 2007 to 2011. Since 2012, with the emergence of income from health materials, the proportion of administrative expenses has been maintained at an average level of about 10\% in 2017 .

\subsubsection{Analysis of the balance rate of income and expenditure of non-profit medical institutions in Chongqing}

Business balance is the basis for the survival and development of a hospital, the basic index to measure the profitability of a hospital, and the basic basis for the government, hospital managers, investors and creditors to make relevant decisions ${ }^{[1]}$. As shown in Table 2, the balance rate of medical revenue and expenditure and the balance rate of drug revenue and expenditure of all nonprofit medical institutions in Chongqing decreased significantly from 2007 to 2017, especially in 2012, where the balance rate of medical revenue and expenditure decreased by $69 \%$ and the balance rate of drug revenue and expenditure decreased by $86 \%$. On the other hand, the balance rate of financial subsidies remained basically stable, at an average level of $62 \%$ from 2007 to 2017 . The balance rate of other income and expenditure balance (the sum of income from health materials and other income minus administrative expenses) has been increasing year by year since 2012, and a positive balance appeared for the first time in 2017. 
Table 2: income and expenditure surplus of non-profit medical institutions in Chongqing

\begin{tabular}{|c|c|c|c|c|c|}
\hline Year & $\begin{array}{c}\text { Total balance } \\
\text { ratio }\end{array}$ & $\begin{array}{c}\text { Balance rate of } \\
\text { medical income } \\
\text { and expenditure }\end{array}$ & $\begin{array}{c}\text { Drug balance } \\
\text { rate }\end{array}$ & $\begin{array}{c}\text { Balance rate of } \\
\text { financial } \\
\text { subsidy }\end{array}$ & $\begin{array}{c}\text { Balance rate of } \\
\text { other income and } \\
\text { expenditure }\end{array}$ \\
\hline 2007 & $4.75 \%$ & $45.35 \%$ & $100.00 \%$ & $64.23 \%$ & - \\
\hline 2008 & $5.63 \%$ & $62.81 \%$ & $100.00 \%$ & $65.62 \%$ & - \\
\hline 2009 & $5.31 \%$ & $46.32 \%$ & $96.97 \%$ & $55.46 \%$ & - \\
\hline 2010 & $6.64 \%$ & $45.35 \%$ & $97.08 \%$ & $56.11 \%$ & - \\
\hline 2011 & $5.44 \%$ & $38.95 \%$ & $96.65 \%$ & $66.44 \%$ & - \\
\hline 2012 & $6.18 \%$ & $11.97 \%$ & $13.82 \%$ & $75.52 \%$ & $-31.96 \%$ \\
\hline 2013 & $6.25 \%$ & $12.94 \%$ & $13.42 \%$ & $62.05 \%$ & $-16.55 \%$ \\
\hline 2014 & $6.61 \%$ & $12.54 \%$ & $12.81 \%$ & $63.40 \%$ & $-6.79 \%$ \\
\hline 2015 & $5.75 \%$ & $10.91 \%$ & $12.70 \%$ & $60.71 \%$ & $-7.82 \%$ \\
\hline 2016 & $4.20 \%$ & $10.47 \%$ & $11.52 \%$ & $59.20 \%$ & $-3.61 \%$ \\
\hline 2017 & $4.51 \%$ & $9.31 \%$ & $8.71 \%$ & $56.50 \%$ & $9.70 \%$ \\
\hline
\end{tabular}

\subsection{Using DuPont analysis method to analyze the composition of net asset balance ratio of non- profit medical institutions in Chongqing}

The "private hospitals" in the table refer to 18 private hospitals listed in the national small and medium-sized enterprise share transfer system (the "new third board"), the data source is the audit annual report of each private hospital from 2015 to 2017, and the corresponding average financial indicators are calculated for comparative analysis. It can be seen that the revenue and expenditure saving rate of non-profit medical institutions in Chongqing is far lower than that of private hospitals in the control group. Although the total asset turnover rate and equity multiplier are higher than those of private hospitals, the return on net assets is still far lower than that of private hospitals, in Table 3.

Table 3: DuPont analysis of roe

\begin{tabular}{|c|c|c|c|c|}
\hline Year & $\begin{array}{c}\text { Return } \\
\text { on net } \\
\text { assets }\end{array}$ & $\begin{array}{c}\text { Business } \\
\text { balance } \\
\text { ratio }\end{array}$ & $\begin{array}{c}\text { Turnover } \\
\text { of total } \\
\text { assets }\end{array}$ & $\begin{array}{c}\text { Equity } \\
\text { multiplier }\end{array}$ \\
\hline 2007 & $6.25 \%$ & $4.75 \%$ & 0.92 & 1.43 \\
\hline 2008 & $12.48 \%$ & $5.63 \%$ & 1.55 & 1.43 \\
\hline 2009 & $7.65 \%$ & $5.31 \%$ & 1.00 & 1.44 \\
\hline 2010 & $9.24 \%$ & $6.64 \%$ & 0.98 & 1.42 \\
\hline 2011 & $8.94 \%$ & $5.44 \%$ & 1.06 & 1.55 \\
\hline 2012 & $13.02 \%$ & $6.18 \%$ & 1.17 & 1.80 \\
\hline 2013 & $13.41 \%$ & $6.25 \%$ & 1.16 & 1.85 \\
\hline 2014 & $9.89 \%$ & $6.61 \%$ & 0.88 & 1.70 \\
\hline 2015 & $11.80 \%$ & $5.75 \%$ & 1.08 & 1.90 \\
\hline 2016 & $8.01 \%$ & $4.20 \%$ & 1.02 & 1.87 \\
\hline 2017 & $8.77 \%$ & $4.51 \%$ & 1.04 & 1.87 \\
\hline
\end{tabular}

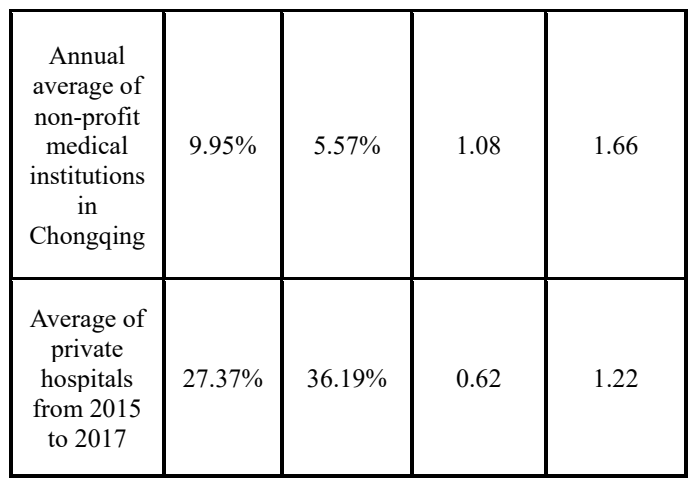

\section{Conclusions}

Through statistical analysis, we can see that the scale of non-profit medical institutions in Chongqing has been expanding in recent 11 years, the total revenue and expenditure has increased year by year with GDP, the overall asset structure is more appropriate, but the profitability has not improved significantly. Since 2012, the income and expenditure structure of non-profit medical institutions in Chongqing has undergone significant changes, which are mainly manifested in the rising proportion of health materials income and management expenses, the decreasing proportion of medical expenses and the increasing proportion of drug expenses, while the proportion of inpatient income, outpatient income and drug income as the main source of income has not changed significantly. 2012 is the key year for deepening the reform of the medical and health system, and the first year for the comprehensive implementation of the plan and implementation plan for deepening the reform of the medical and health system during the 12th Five Year Plan period. We should continue to strengthen the adjustment of drug prices, consolidate the essential drug system implemented since 2009, and reduce the drug expenditure of public hospitals [4]. However, from the 
perspective of the actual revenue and expenditure structure of non-profit medical institutions in Chongqing, the proportion of drug expenditure in the total expenditure increased by leaps and bounds in 2012, while the proportion of drug income in the middle income did not decrease significantly. It can be seen that medical institutions have a long way to go to reduce the cost of drug expenditure and strengthen the adjustment of drug prices.

From the perspective of operating efficiency, the leverage ratio of non-profit medical institutions in Chongqing is much higher than that of private hospitals in the control group, and the asset utilization efficiency is also higher than the average level of private hospitals in the control group. However, due to the high operating cost of non-profit medical institutions in Chongqing, the balance ratio of business income and expenditure is far lower than that of private enterprises in the control group. Even by improving the debt and enhancing the efficiency of asset utilization, the return on net assets can not be significantly improved. The non-profit medical institutions in Chongqing should firmly grasp the national medical reform policy, and focus on reducing the cost, especially the cost of drug expenditure in the future. This is not only in line with the national policy, but also can effectively improve the profitability of medical institutions.

\section{Acknowledgments}

Chongqing Education Science "13th five year plan" project (2020-yq-06); The novel coronavirus pneumonia prevention and control emergency research (Management) special project (2020YJ01), Medical University Of Chongqing School of public health and management

\section{References}

1. $\mathrm{Xu} X . Z$..Discussion on the quality of the balance of the current hospital business income and expenditure [J].Health Economics Research.2007, (10):54-55

2. Hao G.Z. On market financing and risk control measures of public hospitals [J].Money China.2016,(3):89

3. Xiao L.Discussion on the construction of hospital financial analysis index system -- Based on the combination of wall's comprehensive scoring method and DuPont's financial analysis method [J] Health Economics Research.2013,(3):53-55

4. General Office of the State Council. Notice on printing and distributing the main work arrangements for deepening the reform of the medical and health system in 2012 (GBF [2012] No. 20). 2012-04-14 http://www.gov.cn/zwgk/2012-

04/18/content_2115928.htm 